\title{
Obestatin stimulates differentiation and regulates lipolysis and leptin secretion in rat preadipocytes
}

\author{
TATIANA WOJCIECHOWICZ ${ }^{1}$, MAREK SKRZYPSKI ${ }^{1}$, PAWE€ A. KOŁODZIEJSKI ${ }^{1}$, DAWID SZCZEPANKIEWICZ ${ }^{1}$, \\ EWA PRUSZYŃSKA-OSZMAŁEK ${ }^{1}$, PRZEMYSŁAW KACZMAREK ${ }^{1}$, \\ MATHIAS Z. STROWSKI ${ }^{2,3}$ and KRZYSZTOF W. NOWAK ${ }^{1}$
}

${ }^{1}$ Department of Animal Physiology and Biochemistry, Poznań University of Life Sciences, Poznań 60-637, Poland;

${ }^{2}$ Department of Hepatology and Gastroenterology and the Interdisciplinary Centre of Metabolism: Endocrinology,

Diabetes and Metabolism, Charite-University Medicine Berlin, Berlin D-13353;

${ }^{3}$ Medical Clinic 1, Department of Gastroenterology, Elblandklinik, Meissen D-01662, Germany

Received May 5, 2015; Accepted September 25, 2015

DOI: $10.3892 / \mathrm{mmr} .2015 .4470$

\begin{abstract}
Obestatin is a 23 -amino acid peptide encoded by the ghrelin gene, which regulates food intake, body weight and insulin sensitivity. Obestatin influences glucose and lipid metabolism in mature adipocytes in rodents. However, the role of this peptide in rat preadipocytes remains to be fully understood. The current study characterized the effects of obestatin on lipid accumulation, preadipocyte differentiation, lipolysis and leptin secretion in rat primary preadipocytes. Obestatin enhanced lipid accumulation in rat preadipocytes and increased the expression of surrogate markers of preadipocyte differentiation. At the early stage of differentiation, obestatin suppressed lipolysis. By contrast, lipolysis was stimulated at the late stage of adipogenesis. Furthermore, obestatin stimulated the release of leptin, a key satiety hormone. Overall, the results indicated that obestatin promotes preadipocyte differentiation. Obestatin increased leptin release in preadipocytes, while the modulation of lipolysis appears to depend upon the stage of differentiation.
\end{abstract}

\section{Introduction}

Increased differentiation of fat precursor cells, preadipocytes, into mature adipocytes leads to fat tissue hypertrophy and obesity (1). However, impaired differentiation of preadipocytes in the abdominal adipose tissue positively correlates with insulin resistance in obese patients (2). Thus, modulation of preadipocyte differentiation into adipocytes may be an attractive approach in the therapy of obesity and obesity-associated metabolic disorders. A previous study demonstrated that appetite-regulating

Correspondence to: Dr Marek Skrzypski, Department of Animal Physiology and Biochemistry, Poznań University of Life Sciences, 35 Wolyńska Street, Poznań 60-637, Poland

E-mail:mskrzyps@up.poznan.pl

Key words: adipocytes, differentiation, leptin, lipolysis, obestatin, preadipocytes peptides such as orexin A, neuropeptide B and $\mathrm{W}$, and fibroblast growth factor-21 modulate the various functions of mature adipocytes in addition to their precursor cells, preadipocytes (3-6). In addition, previous studies have demonstrated that the metabolic and endocrine functions of adipose tissue are influenced by obestatin, an appetite-regulating peptide hormone $(7,8)$. Obestatin, a 23 -amino acid peptide, is the product of the proteolytic cleavage of preproghrelin (9). Preproghrelin is predominantly expressed in the stomach (9), with lower expression observed in other tissues, such as adipocytes (7) and the pancreas (10). Obestatin was first identified as a hormone that maintains energy homeostasis by inhibiting food intake, delaying gastric emptying and facilitating body weight loss (9). Furthermore, there is growing evidence indicating that obestatin modulates the lipid and glucose metabolism by acting directly on adipocytes. Obestatin activates protein kinase B signaling and stimulates glucose uptake in 3T3-L1 adipocytes (7). In addition, obestatin was reported to influence the lipid metabolism by stimulating lipid accumulation and inhibiting lipolysis in 3T3-L1 cells and human adipocytes $(8,11)$. By contrast, a previous study demonstrated that obestatin suppresses glucose uptake and lipogenesis, whereas it potentiates adrenalin-induced lipolysis in rat primary adipocytes (12). Studies investigating the influence of obestatin on adipogenesis have produced contradictory results. Although it was initially observed that obestatin inhibits differentiation and proliferation of 3T3-L1 preadipocytes (13), later studies indicated that obestatin promotes the proliferation and differentiation of 3T3-L1 preadipocytes into mature adipocytes $(7,8,11)$. However, alternative studies have demonstrated that obestatin failed to influence the differentiation of 3T3-L1 preadipocytes (14). Thus, the role of obestatin in controlling preadipocyte differentiation remains to be fully understood. Therefore, the aim of the current study was to investigate the role of obestatin in regulating rat primary preadipocyte differentiation, lipid metabolism and leptin secretion.

The present study investigated whether obestatin enhanced differentiation of rat preadipocytes by measuring lipid accumulation and the expression of adipogenic transcription factors. Furthermore, the differential effects of obestatin on lipolysis at the early and late stages of differentiation were investigated. 


\section{Materials and methods}

Chemicals. Obestatin was purchased from Sigma-Aldrich (St. Louis, MO, USA). Gibco Dulbecco's modified Eagle's medium (DMEM/F12) media for cell culture was obtained from Thermo Fisher Scientific, Inc., (Waltham, MA, USA). Unless otherwise stated, all additional reagents were obtained from Sigma-Aldrich.

Animals. For independent isolations of preadipocytes, eight rats were used. Male Wistar rats, weighing 80-100 g (age, 5-6 weeks) were maintained on a $12: 12$ light-dark cycle at $21^{\circ} \mathrm{C}$ and fed ad libitum with standard chow. The rats were sacrificed by decapitation according to the approval of the Local Ethics Commission for Investigations on Animals (National Ethics Commission for Investigations on Animals, Ministry of Science and Higher Education, Poznań, Poland).

Preadipocyte isolation and culture. Stromal-vascular cells (preadipocytes) were isolated from epididymal adipose fat pads, as previously described (15) with modifications. Following the removal of blood vessels, the pooled tissue was washed three times in sterile Krebs-Ringer buffer $[118 \mathrm{mM} \mathrm{NaCl}$, $4.8 \mathrm{mM} \mathrm{KCl}, 1.3 \mathrm{mM} \mathrm{CaCl}_{2}, 1.2 \mathrm{mM} \mathrm{KH}_{2} \mathrm{PO}_{4}, 1.2 \mathrm{mM} \mathrm{MgSO}_{4}$, $24.8 \mathrm{mM} \mathrm{NaHCO}{ }_{3}, 10 \mathrm{mM}$ 4-(2-hydroxyethyl)-1-piperazineethanesulfonic acid] supplemented with $3 \%$ bovine serum albumin, $5 \mathrm{mM}$ glucose and antibiotics $(100 \mathrm{U} / \mathrm{ml}$ penicillin and $0.1 \mathrm{mg} / \mathrm{ml}$ streptomycin). Tissue was minced using scissors and digested with collagenase type II at $3 \mathrm{mg} / \mathrm{ml}$ for $45 \mathrm{~min}$ at $37^{\circ} \mathrm{C}$, with gentle agitation. The cell suspension was filtered through $100 \mu \mathrm{m}$ nylon mesh to discard the remaining undigested tissue debris and centrifuged at $450 \mathrm{x}$ g for $10 \mathrm{~min}$ at room temperature (RT). The infranatant containing mature adipocytes was discarded and Red Blood Cell Lysing buffer (Sigma-Aldrich) was added to lyse the erythrocytes. Subsequently, cells were filtered through a $45 \mu \mathrm{m}$ mesh and centrifuged $(450 \mathrm{x} \mathrm{g}$, $10 \mathrm{~min}$ at RT). The cell pellet was resuspended in DMEM/F12 containing 10\% fetal bovine serum and antibiotics. Following cell counting with $0.4 \%$ trypan blue (cell viability $>95 \%$ ) cells were seeded in multi-well plates and cultured for $24 \mathrm{~h}$. Cell culture was performed at $37^{\circ} \mathrm{C}$ in a humidified atmosphere of $95 \%$ air with $5 \% \mathrm{CO}_{2}$. Subsequently, preadipocytes were differentiated in serum-free DMEM/F12 containing adipogenesis-promoting agents ( $30 \mathrm{nM}$ dexamethasone, $167 \mathrm{nM}$ insulin and $2 \mathrm{nM}$ triiodothyronine) in the absence or presence of obestatin $(1,10$ or $100 \mathrm{nM})$. Preadipocytes were differentiated for 1,2, 4 and 5 days. The media was then collected and stored at $-20^{\circ} \mathrm{C}$ for determination of leptin and glycerol concentrations. Simultaneously, cells were harvested and stored at $-80^{\circ} \mathrm{C}$ in Tripure reagent (Roche Diagnostics, Basel, Switzerland) for RNA extraction. Separate experiments were performed for oil red O (ORO) staining.

ORO staining. Preadipocytes were washed with phosphate-buffered saline (PBS) and fixed with 10\% formaldehyde in PBS for $5 \mathrm{~min}$. Following this, the formaldehyde solution was replaced with fresh formaldehyde and fixed for $1 \mathrm{~h}$ at RT. Working ORO solution was prepared prior to each experiment by mixing 6 parts ORO stock solution $(0.7 \mathrm{~g} / 200 \mathrm{ml}$ isopropanol) with 4 parts distilled water and incubating for $20 \mathrm{~min}$ at RT, followed by filtration through a $0.2 \mu \mathrm{m}$ syringe filter. Fixed cells were washed with $60 \%$ isopropanol, completely dried and stained with ORO working solution for $10 \mathrm{~min}$ at RT. Subsequently, cells were washed four times with distilled water and photographed using an LSM 510 inverted microscope and AxioVision Rel. software, version 4.6 (Carl Zeiss, Oberkochen, Germany). For quantification, cells were dried and ORO was eluted by adding $100 \%$ isopropanol. Eluates were then transferred to 96-well plates and the absorbance was measured at a wavelength of $520 \mathrm{~nm}$ using a Synergy 2 Multi-Mode Microplate Reader (BioTek Instruments, Inc., Winooski, VT, USA).

Reverse transcription-quantitative polymerase chain reaction. Total RNA was extracted using TriPure Isolation Reagent (Roche Diagnostics) according to the manufacturer's instructions. First strand cDNA was generated using $0.5 \mu \mathrm{g}$ total RNA and a Transcriptor First Strand cDNA Synthesis kit (Roche Diagnostics). Gene specific primers and probes were designed using Roche software (http://qper.probefinder.com/organism. jsp), and are presented in Table I. Multiplex real-time expression was conducted using Light Cycler TaqMan Master kit in a Light Cycler 2.0 (Roche Diagnostics) using the following thermocycling conditions: cDNA was initially pre-denaturated at $95^{\circ} \mathrm{C}$ for $10 \mathrm{~min}$, followed by 40 cycles of denaturation at $95^{\circ} \mathrm{C}$ for $10 \mathrm{sec}$, annealing at $58^{\circ} \mathrm{C}$ for $30 \mathrm{sec}$ and extension at $72^{\circ} \mathrm{C}$ for $8 \mathrm{sec}$. Analysis of gene expressions was conducted using Light Cycler software, version 4.5 (Roche Diagnostics). The results are based on the relative quantification method with efficiency correction (standard curve method) (16). Results are presented as a ratio of the detected gene expression to the expression of the glyceraldehyde 3-phosphate dehydrogenase gene.

Lipolysis assay. Lipolysis was analyzed by the determination of glycerol release. The glycerol concentration in the medium was measured using a Free Glycerol Determination kit (Sigma-Aldrich), according to the manufacturer's instructions. The absorbance reading was performed at $540 \mathrm{~nm}$ using a Synergy 2 Multi-Mode Microplate Reader.

Leptin secretion assay. The leptin concentration in the culture media was measured using a Rat Leptin Radio Immuno Assay kit (Merck Millipore, Darmstad, Germany), according to the manufacturer's instructions. The assay's sensitivity was $0.639 \mathrm{ng} / \mathrm{ml}$.

Statistical analysis. Analysis of variance followed by the Bonferroni post hoc test were used to determine statistical significance. $\mathrm{P}<0.05$ was considered to indicate a statistically significant difference. Data are presented as the mean \pm standard error, and are derived from experiments conducted a minimum of four times. GraphPad Prism 5.0 (GraphPad Software, Inc., La Jolla, CA, USA) was used for all statistical analyses.

\section{Results}

Obestatin increases triacylglycerol accumulation in rat adipocytes. The effect of obestatin on rat preadipocytes differentiation was investigated by measuring the lipid accumulation and evaluating the morphology of the cells. Obestatin (1-100 nM) increased intracellular triacylglycerol 
Table I.Primer sequences used for measurement of PPAR $\gamma, \mathrm{C} / \mathrm{EBP} \alpha$ and $\mathrm{C} / \mathrm{EBP} \beta$ expression using reverse transcription-quantitative polymerase chain reaction.

\begin{tabular}{llc}
\hline Gene & \multicolumn{1}{c}{ Primer sequence } & Product size (nt) \\
\hline PPAR $\gamma$ & Forward 5'-CAGGAAAGACAACAGACAAATCA-3' & 95 \\
$($ NM_013124.3) & Reverse 5'-GGGGGTGATATGTTTGAACTTG-3' & \\
C/EBP $\alpha$ & Forward 5'-ATAAAGCCAAACAGCGCAAC-3' & 67 \\
$($ NM_012524.2) & Reverse 5'-CGGTCATTGTCACTGGTCAA-3' & 88 \\
C/EBP $\beta$ & Forward 5'-CTTCAGCCCCTACCTGGAG-3' & \\
(NM_024125.4) & Reverse 5'-GAGGTCGGAAAGGAAGTCGT-3' & 92 \\
$($ ENSRNOT00000025351) & Forward 5'-CTGCACCACCAACTGCTTAG-3' & \\
\hline
\end{tabular}

PPAR $\gamma$, peroxisome proliferator-activated receptor $\gamma$; C/EBP, CCAAT-enhancer-binding protein; nt, nucleotides.

Table II. Effects of obestatin on PPAR $\gamma, \mathrm{C} / \mathrm{EBP} \alpha$ and $\mathrm{C} / \mathrm{EBP} \beta$ mRNA expression in rat preadipocytes.

\begin{tabular}{|c|c|c|c|c|}
\hline \multirow[b]{2}{*}{ Day } & \multirow[b]{2}{*}{ Obestatin (nM) } & \multicolumn{3}{|c|}{ Gene } \\
\hline & & $\operatorname{PPAR} \gamma$ & $\mathrm{C} / \mathrm{EBP} \alpha$ & $\mathrm{C} / \mathrm{EBP} \beta$ \\
\hline \multirow[t]{4}{*}{1} & 0 & $1.000 \pm 0.010$ & $1.000 \pm 0.028$ & $1.000 \pm 0.039$ \\
\hline & 1 & $0.952 \pm 0.011$ & $1.250 \pm 0.020^{\mathrm{b}}$ & $1.133 \pm 0.034^{\mathrm{a}}$ \\
\hline & 10 & $0.932 \pm 0.010$ & $1.048 \pm 0.041$ & $1.108 \pm 0.019^{a}$ \\
\hline & 100 & $0.969 \pm 0.012$ & $1.139 \pm 0.046$ & $1.075 \pm 0.013$ \\
\hline \multirow[t]{4}{*}{2} & 0 & $1.000 \pm 0.002$ & $1.000 \pm 0.015$ & $1.000 \pm 0.011$ \\
\hline & 1 & $0.967 \pm 0.010$ & $1.307 \pm 0.068^{\mathrm{a}}$ & $1.013 \pm 0.026$ \\
\hline & 10 & $1.018 \pm 0.005$ & $1.571 \pm 0.096^{\mathrm{b}}$ & $1.041 \pm 0.018$ \\
\hline & 100 & $1.046 \pm 0.010^{\mathrm{b}}$ & $1.250 \pm 0.016$ & $0.988 \pm 0.018$ \\
\hline \multirow[t]{4}{*}{4} & 0 & $1.000 \pm 0.013$ & $1.000 \pm 0.032$ & $1.000 \pm 0.033$ \\
\hline & 1 & $1.245 \pm 0.017^{\mathrm{b}}$ & $1.144 \pm 0.038^{\mathrm{a}}$ & $1.128 \pm 0.043$ \\
\hline & 10 & $1.123 \pm 0.016^{\mathrm{b}}$ & $1.045 \pm 0.020$ & $1.078 \pm 0.039$ \\
\hline & 100 & $1.069 \pm 0.012^{\mathrm{a}}$ & $1.173 \pm 0.039^{\mathrm{a}}$ & $1.104 \pm 0.026$ \\
\hline \multirow[t]{4}{*}{5} & 0 & $1.000 \pm 0.008$ & $1.000 \pm 0.118$ & $1.000 \pm 0.043$ \\
\hline & 1 & $0.992 \pm 0.012$ & $1.646 \pm 0.066$ & $1.140 \pm 0.011$ \\
\hline & 10 & $1.168 \pm 0.018^{\mathrm{b}}$ & $2.215 \pm 0.409^{\mathrm{a}}$ & $1.083 \pm 0.046$ \\
\hline & 100 & $1.116 \pm 0.014^{\mathrm{b}}$ & $2.748 \pm 0.168^{b}$ & $1.067 \pm 0.026$ \\
\hline
\end{tabular}

Cells were differentiated with or without obestatin (1-100 nM). PPAR $\gamma, \mathrm{C} / \mathrm{EBP} \alpha$ and C/EBP $\beta$ expression was evaluated 1, 2, 4 and 5 days following the onset of differentiation. Data are presented as the mean \pm standard error, derived from a minimum of 4 replicates. ${ }^{\mathrm{a}} \mathrm{P}<0.05$, ${ }^{\mathrm{b}} \mathrm{P}<0.01$ vs. untreated cells. PPAR $\gamma$, peroxisome proliferator-activated receptor $\gamma ; \mathrm{C} / \mathrm{EBP}, \mathrm{CCAAT}$-enhancer-binding protein.

content at $24 \mathrm{~h}$ following the initiation of differentiation (Fig. 1A). Increased intracellular triacylglycerol content was additionally observed in cells exposed to 10 and $100 \mathrm{nM}$ obestatin for $48 \mathrm{~h}$ (Fig. 1B). The obestatin-mediated increase in lipid content was accompanied by the presence of larger lipid droplets (Fig. 1E). Obestatin failed to significantly affect lipid content and preadipocyte morphology at 4 and 5 days following the onset of differentiation (Fig. 1C-E). These results indicate that obestatin enhances triacylglycerol accumulation in rat preadipocytes at an earlier stage of differentiation.
Obestatin stimulates peroxisome proliferator-activated receptor $\gamma(P P A R \gamma), C C A A T$-enhancer-binding protein $\alpha$ $(C / E B P \alpha)$ and $C / E B P \beta$ expression in rat preadipocytes. The effects of obestatin on the expression of PPAR $\gamma, \mathrm{C} / \mathrm{EBP} \alpha$ and $\mathrm{C} / \mathrm{EBP} \beta$ were investigated (Table II). Obestatin at $100 \mathrm{nM}$ significantly increased PPAR $\gamma$ expression at 2 days following the onset of differentiation. Furthermore, obestatin at all tested concentrations increased PPAR $\gamma$ expression at 4 days following the induction of differentiation. The increase in PPAR $\gamma$ expression was additionally observed in preadipocytes differentiated in the presence of 10 or $100 \mathrm{nM}$ obestatin for 5 days. By 
A

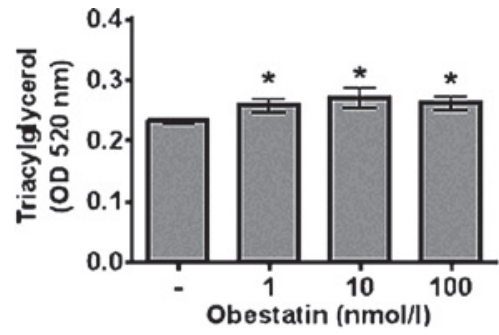

C



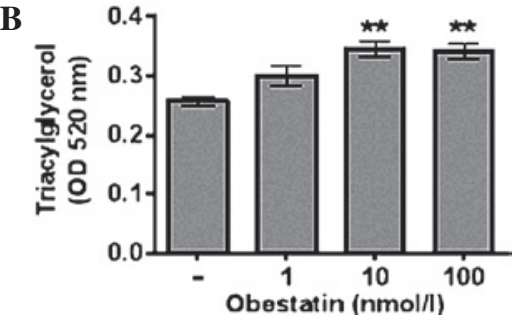

D

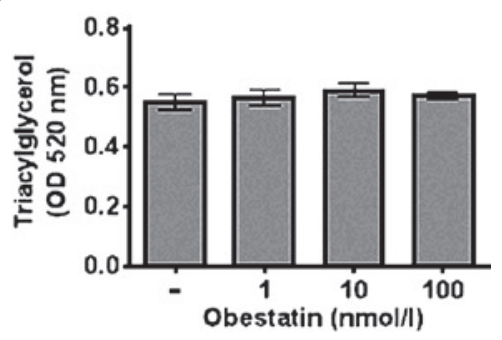

$\mathbf{E}$ Obestatin (nM)

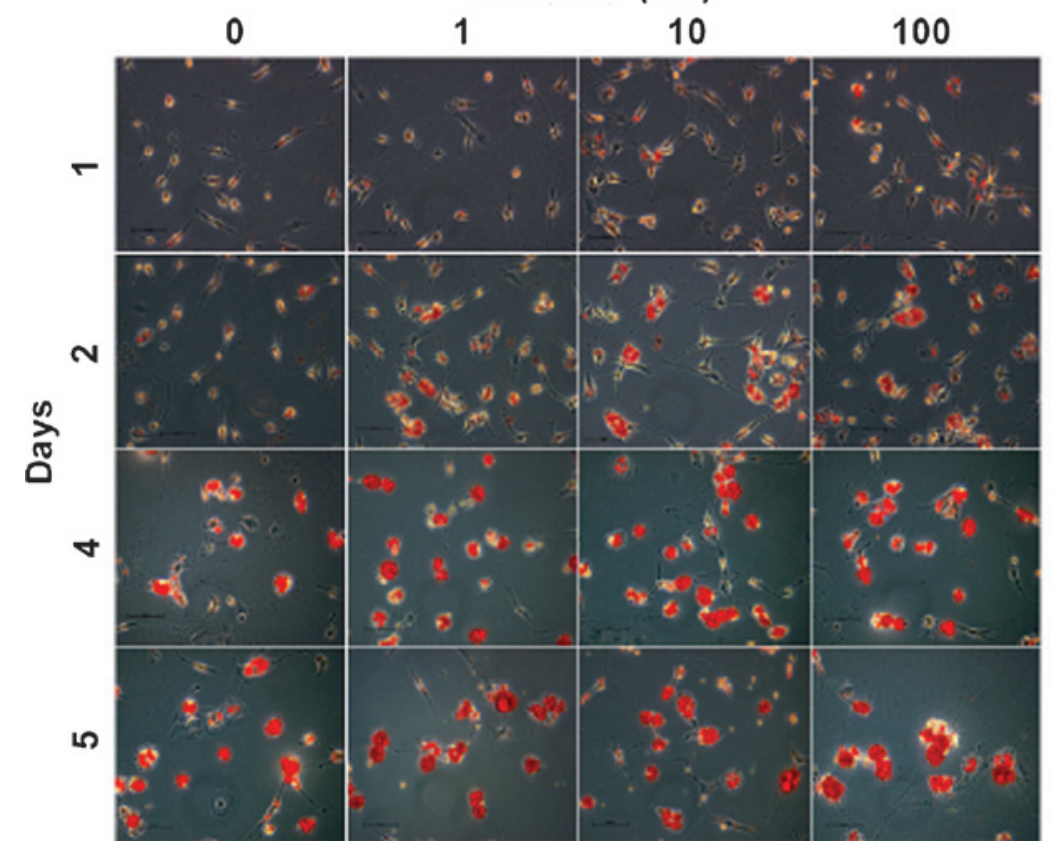

Figure 1. Effects of obestatin (1-100 nM) on triacylglycerol accumulation during differentiation of rat preadipocytes. Quantification of intracellular triacylglycerol content in cells incubated with or without obestatin for (A) 1, (B) 2, (C) 4 and (D) 5 days. (E) Representative images (oil red O staining) of rat preadipocytes differentiated with or without obestatin for 1,2, 4 and 5 days. Images were acquired at a magnification of $x 400$. Data are presented as the mean \pm standard error, derived from a minimum of 4 replicates. ${ }^{*} \mathrm{P}<0.05,{ }^{* *} \mathrm{P}<0.01$ vs. untreated cells. OD, optical density.

contrast, no increase was observed at $24 \mathrm{~h}$ following the onset of differentiation. Obestatin $(1 \mathrm{nM})$ increased $\mathrm{C} / \mathrm{EBP} \alpha$ expression at $24 \mathrm{~h}$ of differentiation. At 2 days of differentiation, obestatin (at 1 and $10 \mathrm{nM}$ ) enhanced $\mathrm{C} / \mathrm{EBP} \alpha$ expression. In addition, the increase in $\mathrm{C} / \mathrm{EBP} \alpha$ expression was observed in preadipocytes exposed to 1 and $100 \mathrm{nM}$ obestatin for 4 days and in cells treated with 10 and $100 \mathrm{nM}$ obestatin for 5 days. C/EBP $\beta$ mRNA expression was upregulated by 1 and $10 \mathrm{nM}$ obestatin following $24 \mathrm{~h}$ of incubation. Thus, obestatin increases adipogenic gene expression in a dose- and time-dependent manner.

Obestatin regulates lipolysis in rat preadipocytes. Glycerol release was analyzed in preadipocytes differentiated in the absence or presence of obestatin for 2, 4 or 5 days. At $100 \mathrm{nM}$, obestatin reduced glycerol release from preadipocytes at 2 days following the onset of differentiation (Fig. 2A). Obestatin failed to influence glycerol release following 4 days of differentiation (Fig. 2B). By contrast, glycerol secretion increased in preadipocytes exposed to 10 and $100 \mathrm{nM}$ obestatin for 5 days (Fig. 2C). These results suggest that obestatin suppresses lipolysis during the first stages of differentiation, whereas it stimulates lipolysis in well-differentiated preadipocytes.

Obestatin stimulates leptin secretion from rat preadipocytes. The effect of obestatin on leptin secretion from rat preadipocytes was investigated during the different stages of the differentiation process. At 10 or $100 \mathrm{nM}$, obestatin increased leptin secretion from preadipocytes at $24 \mathrm{~h}$ following the initiation of differentiation (Fig. 3A). In addition, at 1, 10 and $100 \mathrm{nM}$, obestatin increased leptin secretion from rat preadipocytes following 
A

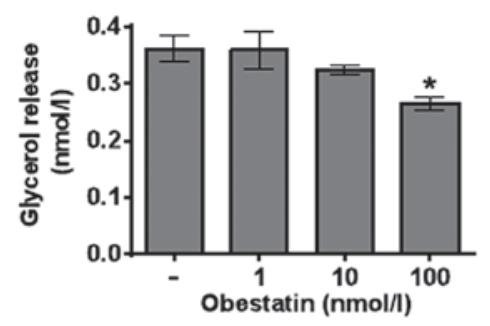

B

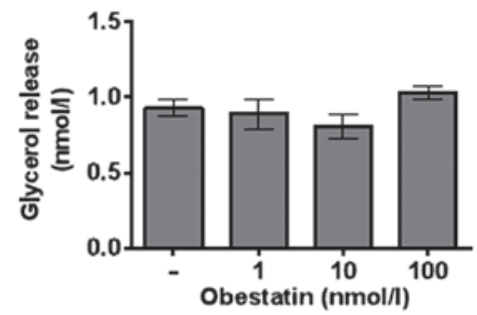

C

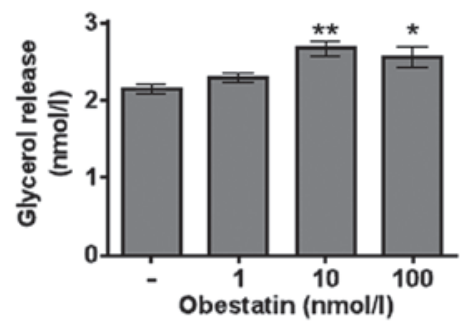

Figure 2. Effects of obestatin (1-100 nM) on glycerol release from rat preadipocytes. Preadipocytes were differentiated with or without obestatin (1-100 nM) for (A) 2, (B) 4 and (C) 5 days, followed by measurement of glycerol in the medium. Data are presented as the mean \pm standard error, derived from a minimum of 4 replicates. ${ }^{*} \mathrm{P}<0.05,{ }^{* * *} \mathrm{P}<0.01$ vs. untreated cells.

4 days of differentiation (Fig. 3C). Obestatin at all tested doses failed to significantly modulate leptin secretion from preadipocytes differentiated for 2 (Fig. 3B) and 5 days (Fig. 3D). These results indicate that obestatin is able to enhance leptin secretion from rat preadipocytes.

\section{Discussion}

A previous study reported that obestatin inhibits lipogenesis and glucose uptake in differentiated rat adipocytes (12). The current study extends these observations by demonstrating that obestatin increases lipid accumulation, enhances preadipocyte differentiation and modulates lipolysis and leptin secretion in rat primary preadipocytes. Furthermore, the results demonstrate that obestatin increases leptin secretion in rat preadipocytes.

Differentiation of preadipocytes into mature adipocytes is accompanied by enhanced triacylglycerol accumulation (17). The current study observed that obestatin increased early intracellular triacylglycerol accumulation in preadipocytes. As a hallmark of adipogenesis (18) the size of lipid droplets in obestatin-treated cells increased, and notably, these effects were detected at 1 or 2 however not 4 or 5 days following the onset of differentiation. These results correspond to previous reports regarding the inability of a 9-day treatment of 3T3-L1 preadipocytes with obestatin to influence lipid content (14). In contrast to these observations, it has been reported that obestatin is able to potentiate lipid accumulation even following 8 and 14 days of differentiation in 3T3-L1 preadipocytes and in human primary subcutaneous preadipocytes (8). Notably, in
A

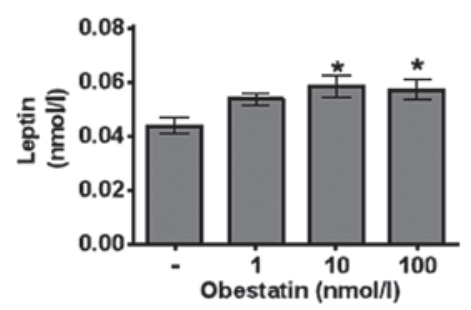

B

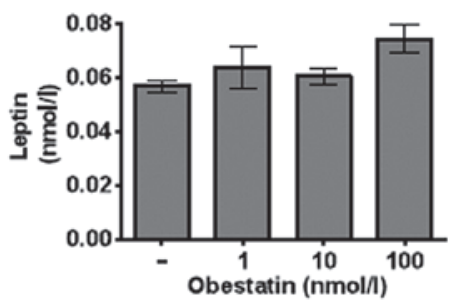

C

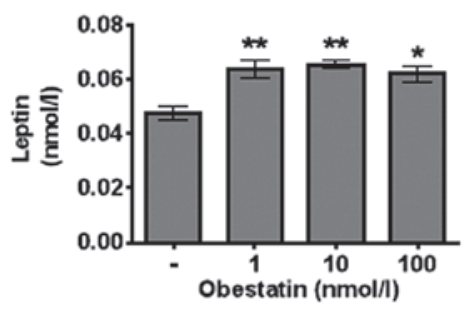

D

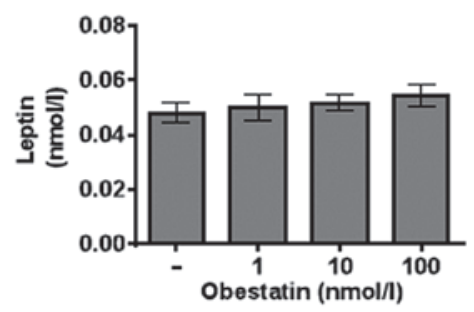

Figure 3. Effects of obestatin $(1-100 \mathrm{nM})$ on leptin secretion from rat preadipocytes. Preadipocytes were differentiated with or without obestatin, and leptin secretion was determined at (A) 1, (B) 2, (C) 4 and (D) 5 days following the onset of differentiation. Data are presented as the mean \pm standard error, derived from a minimum of 4 replicates. ${ }^{*} \mathrm{P}<0.05,{ }^{* *} \mathrm{P}<0.01$ vs. untreated cells.

the same study obestatin failed to affect lipid accumulation in omental preadipocytes obtained from lean humans, whereas it enhanced lipid accumulation in preadipocytes isolated from obese individuals (8). These conflicting data may result either from different experimental methodology or the health conditions of the preadipocytes donors.

Although differentiation of fat precursor cells into mature adipocytes is modulated by a variety of transcription factors (17), there is convincing evidence that the expression of numerous genes which induce and maintain adipognesis is coordinated by PPAR $\gamma$ and the C/EBPs $(17,19,20)$. In the current study, obestatin increased PPAR $\gamma, \mathrm{C} / \mathrm{EBP} \alpha$ and $\mathrm{C} / \mathrm{EBP} \beta$ expression in rat preadipocytes. It should be emphasized that these effects were time- and dose-dependent. Gene expression was more potently stimulated by the lower doses of obestatin. This observation is in line with a previous report indicating that obestatin enhances 3T3-L1 preadipocyte proliferation only at lower concentrations (14). It cannot be ruled out that the dynamic and dose-dependent effects of obestatin on preadipocytes may result from obestatin receptor desensitization.

However, as obestatin was observed to stimulate lipid accumulation in addition to potentiating the expression 
of genes which regulate adipogenesis, it is suggested that obestatin promotes the differentiation of rat preadipocytes. Of note, the adipogenic role of this peptide is supported by studies demonstrating that obestatin promotes adipogenesis in 3T3-L1 cells (7) and in porcine preadipocytes (21).

A previous study indicated that obestatin promotes lipolysis and suppresses lipogenesis in fully differentiated rat adipocytes (12). In the current study, the consequences of obestatin treatment on glycerol release during the differentiation of preadipocytes was investigated. These data demonstrated that obestatin suppresses glycerol release following 2 days of differentiation. By contrast, obestatin enhances glycerol release from cells that were continually exposed to obestatin for 5 days. These data suggest that the effects of obestatin on lipid metabolism in rat adipocytes are biphasic. Obestatin appears to enhance lipid accumulation at an early stage of differentiation, which may result from enhanced adipogenesis, whereas it inhibits lipogenesis in mature adipocytes. Furthermore, this suggests that obestatin may only induce lipolysis in well-differentiated fat cells. This suggestion is supported by a previous study demonstrating that obestatin promotes free fatty acid release from 3T3-L1 adipocytes (14). The same study indicated that cell-permeable TAT-obestatin is able to evoke free fatty acid and glycerol release from 3T3-L1 adipocytes (14). However, conflicting studies have reported that obestatin suppresses lipolysis in 3T3-L1 adipocytes and in human adipocytes $(8,11)$. Overall, the influence of obestatin on adipocytes lipid metabolism is complex and requires further investigation.

Furthermore, the current study observed that obestatin increased leptin secretion from rat preadipocytes. Notably, leptin enhanced rat preadipocyte differentiation in vitro (22). Leptin inhibits glucose transport and triggers lipolysis in mature rat white adipocytes $(23,24)$. These observations support the hypothesis that the effects of obestatin on rat preadipocytes (enhanced differentiation) and adipocytes (lipolysis) may be contributed to by enhanced leptin secretion. However, in contrast with the results of the current study, others have observed obestatin to inhibit leptin secretion in human preadipocytes (8). Why obestatin selectively stimulates leptin secretion in rat adipocytes whilst suppressing secretion from human preadipocytes remains unclear. However, it cannot be ruled out that this is due to the different receptors conferring the effects of obestatin in rat and human adipocytes. It remains to be fully elucidated whether obestatin binds to $G$ protein-coupled receptor 37 (GPR37) or/and to glucagon-like peptide-1 receptor (GLP1R), however GPR37 and GLP1R have been previously reported as obestatin receptors in adipocytes $(7,8,12)$. Furthermore, it has been suggested that the presence of intracellular receptors conferring the metabolic effects of obestatin cannot be excluded $(14,25)$.

In conclusion, the current study demonstrates that obestatin stimulates early lipid accumulation and the expression of adipogenic genes, and provides evidence that obestatin stimulates leptin secretion from preadipocytes.

\section{Acknowledgements}

The current study was supported by a grant from the Polish Ministry of Science and Higher Education to Dr Tatiana Wojciechowicz (grant no. N N303 319337).

\section{References}

1. Stephens JM: The fat controller: Adipocyte development. PLoS Biol 10: e1001436, 2012.

2. Isakson P, Hammarstedt A, Gustafson B and Smith U: Impaired preadipocyte differentiation in human abdominal obesity: Role of Wnt, tumor necrosis factor-alpha, and inflammation. Diabetes 58: 1550-1557, 2009.

3. Skrzypski M, T Le T, Kaczmarek P, Pruszynska-Oszmalek E, Pietrzak P, Szczepankiewicz D, Kolodziejski PA, Sassek M, Arafat A, Wiedenmann B, et al: Orexin A stimulates glucose uptake, lipid accumulation and adiponectin secretion from 3T3-L1 adipocytes and isolated primary rat adipocytes. Diabetologia 54: 1841-1852, 2011.

4. Skrzypski M, Pruszyńska-Oszmałek E, Ruciński M, Szczepankiewicz D, Sassek M, Wojciechowicz T, Kaczmarek P, Kołodziejski PA, Strowski MZ, Malendowicz LK and Nowak KW: Neuropeptide B and W regulate leptin and resistin secretion, and stimulate lipolysis in isolated rat adipocytes. Regul Pept 176: 51-56, 2012.

5. Skrzypski M, Kaczmarek P, Le TT, Wojciechowicz T, Pruszyńska-Oszmalek E, Szczepankiewicz D, Sassek M, Arafat A, Wiedenmann B, Nowak KW and Strowski MZ: Effects of orexin A on proliferation, survival, apoptosis and differentiation of 3T3-L1 preadipocytes into mature adipocytes. FEBS Lett 586: 4157-4164, 2012.

6. Arafat AM,Kaczmarek P, Skrzypski M,Pruszyńska-Oszmalek E, Kołodziejski P, Szczepankiewicz D, Sassek M, Wojciechowicz T, Wiedenmann B, Pfeiffer AF, et al: Glucagon increases circulating fibroblast growth factor 21 independently of endogenous insulin levels: A novel mechanism of glucagon-stimulated lipolysis? Diabetologia 56: 588-597, 2013.

7. Gurriarán-Rodríguez U, Al-Massadi O, Roca-Rivada A, Crujeiras AB, Gallego R, Pardo M, Seoane LM, Pazos Y, Casanueva FF and Camiña JP: Obestatin as a regulator of adipocyte metabolism and adipogenesis. J Cell Mol Med 15: 1927-1940, 2011

8. Granata R, Gallo D, Luque RM, Baragli A, Scarlatti F, Grande C, Gesmundo I, Córdoba-Chacón J, Bergandi L, Settanni F, et al: Obestatin regulates adipocyte function and protects against diet-induced insulin resistance and inflammation. FASEB J 26: 3393-3411, 2012.

9. Zhang JV, Ren PG, Avsian-Kretchmer O, Luo CW, Rauch R, Klein $\mathrm{C}$ and Hsueh AJ: Obestatin, a peptide encoded by the ghrelin gene, opposes ghrelin's effects on food intake. Science 310: 996-999, 2005.

10. Chanoine JP, Wong AC and Barrios V: Obestatin, acylated and total ghrelin concentrations in the perinatal rat pancreas. Horm Res 66: 81-88, 2006.

11. Miegueu P, St Pierre D, Broglio F and Cianflone K: Effect of desacyl ghrelin, obestatin and related peptides on triglyceride storage, metabolism and GHSR signaling in 3T3-L1 adipocytes. J Cell Biochem 112: 704-714, 2011.

12. Pruszynska-OszmalekE, SzczepankiewiczD,Hertig I,Skrzypski M, Sassek M, Kaczmarek P, Kolodziejski PA, Mackowiak P, Nowak KW, Strowski MZ and Wojciechowicz T: Obestatin inhibits lipogenesis and glucose uptake in isolated primary rat adipocytes. J Biol Regul Homeost Agents 27: 23-33, 2013.

13. Zhang Z, Zou D, Chen Y, Wang M, Wu J and Guo Z: Obestatin inhibits proliferation and differentiation of 3T3-L1 preadipocytes. Acad J Second Mil Med Univ 28: 929-932, 2007 (In Chinese).

14. Ren G, He Z, Cong P, Yu J, Qin Y, Chen Y and Liu X: Effect of TAT-obestatin on proliferation, differentiation, apoptosis and lipolysis in 3T3-L1 preadipocytes. J Pept Sci 19: 684-691, 2013.

15. Shillabeer G, Li ZH, Hatch G, Kumar V and Lau DC: A novel method for studying preadipocyte differentiation in vitro. Int J Obes Relat Metab Disord 20 Suppl 3: S77-83, 1996.

16. Larionov A, Krause A and Miller W: A standard curve based method for relative real time PCR data processing. BMC Bioinformatics 6: 62, 2005.

17. Gregoire FM, Smas CM and Sul HS: Understanding adipocyte differentiation. Physiol Rev 78: 783-809, 1998.

18. Fu Y, Luo N, Klein RL and Garvey WT: Adiponectin promotes adipocyte differentiation, insulin sensitivity, and lipid accumulation. J Lipid Res 46: 1369-1379, 2005.

19. Rosen ED, Sarraf P, Troy AE, Bradwin G, Moore K, Milstone DS, Spiegelman BM and Mortensen RM: PPAR gamma is required for the differentiation of adipose tissue in vivo and in vitro. Mol Cell 4: 611-617, 1999. 
20. Farmer SR: Regulation of PPARgamma activity during adipogenesis. Int J Obes 29 (Suppl 1): S13-S16, 2005.

21. Tang S, Dong $X$ and Zhang W: Obestatin changes proliferation, differentiation and apoptosis of porcine preadipocytes. Ann Endocrinol (Paris) 75: 1-9, 2014.

22. Machinal-Quélin F, Dieudonné MN, Leneveu MC, Pecquery R and Giudicelli Y: Proadipogenic effect of leptin on rat preadipocytes in vitro: Activation of MAPK and STAT3 signaling pathways. Am J Physiol Cell Physiol 282: C853-C863, 2002 .
23. Müller G, Ertl J, Gerl M and Preibisch G: Leptin impairs metabolic actions of insulin in isolated rat adipocytes. J Biol Chem 272: 10585-10593, 1997.

24. Rodríguez VM, Macarulla MT, Echevarría E and Portillo MP: Lipolysis induced by leptin in rat adipose tissue from different anatomical locations. Eur J Nutr 42: 149-153, 2003.

25. Ren G, He Z, Cong P, Chen H, Guo Y, Yu J, Liu Z, Ji Q, Song Z and Chen Y: Peripheral administration of TAT-obestatin can influence the expression of liporegulatory genes but fails to affect food intake in mice. Peptides 42: 8-14, 2013. 